\title{
Anxiety and Depression Symptoms Among Ovarian Cancer Patients in Western China: A Cross-Sectional Study
}

\author{
Jing Chen ${ }^{1,2 *}$, Yanan Yin ${ }^{1,2}$, Derong Long ${ }^{1,2}$, Yi Liu ${ }^{1,2}$ and Yalin $\mathrm{He}^{1,2}$ \\ ${ }^{1}$ Department of Gynecology, West China Second University Hospital, Sichuan University, Chengdu, Sichuan, People's Republic \\ of China
}

${ }^{2}$ Key Laboratory of Birth Defects and Related Diseases of Women and Children (Sichuan University), Ministry of Education Degrees: Jing Chen, Master; Yanan Yin, Master; Yi Liu, Master; Yalin He, Bachelor; Derong Long, Bachelor.

*Corresponding author: Jing Chen, West China Second University Hospital/ Key Laboratory of Birth Defects and Related Diseases of Women and Children, Sichuan University, Chengdu, Sichuan 610041, People's Republic of China

\section{ARTICLE INFO}

Received: 慧 March 20, 2020

Published: 慧 March 30, 2020

Citation: Jing Chen, Yanan Yin, Derong Long, Yi Liu, Yalin He. Anxiety and Depression Symptoms Among Ovarian Cancer Patients in Western China: A Cross-Sectional Study. Biomed J Sci \& Tech Res 26(5)-2020. BJSTR. MS.ID.004404.

Keywords: Ovarian Cancer; Cancer-Related Depression; Cancer-Related Anxiety; Coping Style

Abbreviations: HADS: Hospital Anxiety and Depression Scale; SCSQ: Simplified Coping Style Questionnaire; SDS: Self-rating Depression Scale; BDI: Beck Depression Inventor; GDS: Geriatric Depression Scale; HAMD: Hamilton Depression Rating Scale

\section{ABSTRACT}

Background: It is well known that cancer patients tend to have different degrees of depression and anxiety. However, there are few studies focus on the association between symptoms of depression and anxiety among ovarian cancer patients and their coping styles in western China. In this study, we aim to investigate the prevalence of cancer-related depression and anxiety in western China among patients with ovarian cancer, and analyze their influencing factors, to provide clinical guides for psychological interventions.

Objects and Methods: In this prospective, cross-sectional study, qualified patients were asked to fill in these questionnaires, including Hospital anxiety and depression scale (HADS) and Simplified Coping Style Questionnaire (SCSQ). Multivariate analysis and binary logistic regression analysis were used to test the associations among symptoms of depression and anxiety, coping styles and influencing factors.

Result: A total of 270 questionnaires were distributed in a 3rd-grade women and children hospital of Chengdu since March l, 2016 to March l, 2017. All participants in our study were ovarian cancer inpatients and all questionnaires were valid for analysis. The prevalence of depression and anxiety in ovarian cancer patients were $47.03 \%$ and $57.77 \%$, respectively. $90.38 \%$ of cancer-related anxiety and $91.33 \%$ of cancer-related depression were both mild. Chi-square test showed there were statistically significant differences $(\mathrm{P}<0.05)$ in the fields of education level and income. But age, marital status, medical costs and cancer stage were not significantly correlated with the prevalence of depression and anxiety $(\mathrm{P}<0.05)$. T test showed cancer-related depression and anxiety were associated with coping style, the difference had statistical significance $(\mathrm{P}<0.05)$. Furthermore, the multivariate analysis showed that education and coping style were the independent influencing factors of both cancer-related depression and anxiety.

Conclusion: The present study suggested that about half of ovarian cancer patients were with depression and anxiety symptoms. The majority of the cancerrelated depression and anxiety were mild. Educational level and coping style should be considered during the interventions of cancer-related depression and anxiety.

\section{Introduction}

Ovarian cancer has the highest fatality rate among gynecological oncology in developed countries [1], also in China [2]. All over the world, ovarian cancer was diagnosed in nearly 225,000 women and was responsible for estimated 140,100 deaths in 2017[3]. 
Meantime, the prevalence and mortality of ovarian cancer varies from different countries. It was estimated that, in the United States, 21,200 women are diagnosed with ovarian cancer, and 14,300 die from the disease each year, approximately [4]. In Australia, it was forecasted that near 1480 women would be diagnosed with ovarian cancer, and 1040 cases would die from this disease [5]. And the highest number of deaths $(34,575$ deaths $)$ [6] caused by ovarian cancer were found in Asian and China, with 110,526 diagnoses. The five-year survival rate is nearly $90 \%$ in early stage, but only $30 \%$ in advanced stage [7]. However, it's difficult to diagnose ovarian cancer at early-stage( I / II ) due to the nonspecific symptoms, and there is no recommended screening test. So, the majority of ovarian cancer patients are diagnosed at advanced stage. In Poland, as many as $42.5 \%$ of patients with adenocarcinoma were diagnosed in stage IV [8].

As the high diagnosis rate of advanced-stage and high mortality of the disease, patients who are suffering ovarian cancer have to tolerate not only physical pain, but also enormous psychological pressure and huge financial burden [9,10]. Some studies have indicated that depression and anxiety are two common types of psychological disorders in cancer patients [11-13]. Anxiety is often described as the emotion of fear, involving the feelings of tension, nervousness, worry, apprehension and dread for something perceived as threaten in the further. Depression has been defined as an emotion of sadness, hopelessness, lack of energy and gloom [14]. Among many types of cancer patients, the degree of anxiety in female patients was significantly higher than in male patients, and gynecological cancer patients were regarded to have the highest level of anxiety [15]. In the past, poor mental state is often regarded as a normal phenomenon accompanied by the disease, which led medical workers to ignore these symptoms. But in fact, anxiety, depression and other adverse psychological state will not only affect the patient's subjective feelings, quality of life, but also the disease progression and prognosis [16]. Especially for patients with gynecological oncology, the diseases often cause the loss of function or organism that represents female characteristics, which make the patients feel ashamed. So gynecological cancer patients are more likely to suffer from poor mental state, and interruption treatment than other cancer patients [17]. Several previous studies have shown that a monitoring coping style is related to reduce psychological impact for ovarian cancer $[18,19]$. So, identifying influencing factors associated with poor psychological status is important to develop appropriate target interventions for ovarian cancer patients $[20,21]$. Therefore, we conducted this crosssectional study to assess the prevalence of depression and anxiety in ovarian cancer patients in western China and analyze the related influencing factors.

\section{Methods}

\section{Study Design and Recruitment Criteria}

We carried out a cross-sectional study to assess the symptoms of anxiety and depression among ovarian cancer patients and the influencing factors. This survey was from March 2016 to March 2017, and was demonstrated in West China Second University Hospital, Sichuan University, China. The study was approved by the Ethics Committee of West China Second University Hospital, Sichuan University. All participants in the survey filled in informed consent. Inclusion criteria were

1. Being pathologically diagnosed as epithelial ovarian cancer.

2. Able to read and understand the questionnaire in Chinese.

3. With clear consciousness.

4. Over 18 years old. Exclusion criteria were

a) Had a history of psychiatric disease.

b) Unable or unwilling to fill in informed consent or communicate with study stuff.

c) Accompany other kind of cancers.

\section{Measurements of Anxiety and Depression Symptoms}

We adopted Hospital Anxiety and Depression Scale (HADS) [22] to measure the degree of anxiety and depression symptoms. This 14-item questionnaire includes two subscales, anxiety subscales (seven items) and depression subscales (seven items). Responses for each question range from 0 to $3(0=$ completely not; $1=$ a little; $2=$ somewhat and 3 =very much). The total score point ranges from 0 to 21 . The higher of the score, the severe of anxiety and depression symptom is. The score "less than 8" is within normal range, "8-10" suggests a possible clinical anxiety or depression and "over 10 " indicates a probable anxiety or depression mood disorder. The instrument has been widely used in China with sufficient reliability. The internal reliability alpha valued for the symptoms of anxiety and depression were 0.828 and 0.901 respectively in the current study.

\section{Measurement of Coping Style}

Coping style was measured by the 20-item Simplified Coping Style Questionnaire (SCSQ) [23]. Each item is rated as four-point Likert scale $(0=$ never do; $1=$ seldom do; $2=$ often do and $3=$ always do). This instrument is a self-report questionnaire which contains 20 items and consists of two subscales: positive and negative coping. The high score of each dimension indicated frequent usage of this type of coping. The internal reliability alpha valued for the positive and negative coping style was 0.793 and 0.835 respectively in the current study.

\section{Statistical Analysis}

According to the epidemiology of sample size estimates, the required sample size is 10 times of the research factors and the number of related factors in our study is 10 . Meantime consider about the $20 \%$ loss rate; 120 participants are needed to be enrolled. Pre-survey showed that the prevalence of cancer-related anxiety 
and depression were about $50 \%$, the actual sample should be more than 240 cases. The survey data were entered into Epidata, and specialized software was used for managing data. This program facilitates interactive entry and data correction and maintains consistent and accurate trial data. SPSS 17.0 software package was used for statistical analyses. Chi-square test or T test was used to analyze the statistical differences of qualitative data. Significance was set at $\mathrm{P}<0.05$. In the multivariate analysis, binary logistic regression analysis was used and odds ratios (OR) with $95 \%$ confidence intervals (CI) were calculated.

\section{Result}

Table 1: Clinical and Social-Demographic Data of Patients.

\begin{tabular}{|c|c|c|}
\hline Variable & Number(n) & Percentage (\%) \\
\hline \multicolumn{3}{|c|}{ Age, $y$} \\
\hline $18 \sim 45$ & 87 & 32.22 \\
\hline $45 \sim 60$ & 148 & 54.81 \\
\hline$\geq 60$ & 35 & 12.97 \\
\hline \multicolumn{3}{|c|}{ Marital status } \\
\hline unmarried & 13 & 4.82 \\
\hline married & 257 & 95.18 \\
\hline \multicolumn{3}{|c|}{ Education level } \\
\hline Primary or high school & 177 & 65.55 \\
\hline Bachelor's degree or master & 93 & 34.45 \\
\hline \multicolumn{3}{|c|}{ Family income, Yuan/month } \\
\hline$\leq 3000$ & 115 & 42.59 \\
\hline $3000 \sim 5000$ & 103 & 38.15 \\
\hline$\geq 5000$ & 52 & 19.26 \\
\hline \multicolumn{3}{|c|}{ Cancer staging } \\
\hline III & 195 & 72.22 \\
\hline IV & 75 & 27.78 \\
\hline \multicolumn{3}{|c|}{ Medical costs, Yuan } \\
\hline $20000 \sim 40000$ & 197 & 72.96 \\
\hline$\geq 40000$ & 73 & 27.04 \\
\hline
\end{tabular}

Finally, a total of 270 hospitalized ovarian cancer patients were enrolled in the study. Table 1 presented the patients' characteristics of demographic and clinical variables. Among 270 ovarian cancer patients, there were $148(54.81 \%)$ cases who are $45-60$ years old, the age range was 18 to 82 years $(53.54 \pm 5.49 .95 .18 \%$ ) patients were married, there were $65.55 \%$ of patients graduated from primary and high school and only 52 patients (19.26\%) earned more than 5,000 Yuan per month. The majority of ovarian cancer

Table 2: Clinical and Social-Demographic Data of Patients. patients were under stage- III, accounting for $72.22 \%, 197$ patients (72.96\%) spent 20,000-40,000Yuan when they were hospitalized.

\section{The Prevalence of Cancer-Related Depression and Anxiety}

The prevalence of cancer-related depression was $47.03 \%$ and cancer-related anxiety was $57.77 \%$ among the 270 ovarian cancer patients. Approximately $90.38 \%$ of cancer-related anxiety and $91.33 \%$ of cancer-related depression were both mild (Table 2).

\begin{tabular}{|c|c|c|c|c|c|c|}
\hline \multirow{2}{*}{ Sample size } & \multirow{2}{*}{ Variable } & \multirow{2}{*}{$\mathbf{N}$} & \multirow{2}{*}{ Morbidity (\%) } & \multicolumn{3}{|c|}{ Distribution } \\
\hline & & & & Degree & $\mathbf{n}$ & Composition \\
\hline \multirow{3}{*}{270} & \multirow{3}{*}{ Anxiety } & \multirow{3}{*}{156} & \multirow{3}{*}{57.77} & Mildly & 141 & 90.38 \\
\hline & & & & Moderate & 13 & 8.33 \\
\hline & & & & Severe & 2 & 1.29 \\
\hline \multirow{3}{*}{270} & \multirow{3}{*}{ Depression } & \multirow{3}{*}{127} & \multirow{3}{*}{47.03} & Mildly & 116 & 91.33 \\
\hline & & & & Moderate & 10 & 7.88 \\
\hline & & & & Severe & 1 & 0.79 \\
\hline
\end{tabular}


Associations of Demographic and Clinical Variables with Symptoms of Depression and Anxiety

As shown in Table 3-1 \& 3-2, the prevalence of cancerrelated depression and anxiety were associated with education level and income, there was statistically significant differences in education level (depression: $\mathrm{P}=0.000$, anxiety: $\mathrm{P}=0.009$ ) and income (depression: $\mathrm{P}=0.009$, anxiety: $\mathrm{P}=0.004$ ). Cancer-related depression and anxiety were associated with coping style among the 270 ovarian cancer patients, there was statistically significant differences (depression: $\mathrm{P}=0.032$ for active style and $\mathrm{P}=0.000$ for negative style, anxiety: $\mathrm{P}=0.006$ for active style and $\mathrm{P}=0.000$ for negative style)

Table 3-1: Relation Ship Between Various Factors and Cancer-Related Anxiety, Depression.

\begin{tabular}{|c|c|c|c|c|c|c|c|c|c|c|}
\hline \multirow{2}{*}{ Variable } & \multirow{2}{*}{\multicolumn{2}{|c|}{$\mathbf{N}$}} & \multicolumn{4}{|c|}{ Anxiety } & \multicolumn{4}{|c|}{ Depression } \\
\hline & & & \multirow{2}{*}{$\begin{array}{c}\mathbf{n} \\
49\end{array}$} & \multirow{2}{*}{$\begin{array}{c}\% \\
56.32 \\
\end{array}$} & \multirow[t]{2}{*}{$\mathrm{X}^{2}$} & \multirow[t]{2}{*}{$\mathbf{P}$} & \multirow[t]{2}{*}{$\mathbf{n}$} & \multirow{2}{*}{\begin{tabular}{l|}
$\%$ \\
36 \\
\end{tabular}} & \multirow{2}{*}{$\begin{array}{c}\mathbf{X}^{\mathbf{2}} \\
41.37 \\
\end{array}$} & \multirow[t]{2}{*}{$\mathbf{P}$} \\
\hline \multirow{3}{*}{ Age, y } & $18 \sim 45$ & 87 & & & & & & & & \\
\hline & $45 \sim 60$ & 148 & 84 & 56.75 & 1.043 & 0.594 & 74 & 50 & 1.673 & 0.433 \\
\hline & $\geq 60$ & 35 & 23 & 65.71 & & & & 17 & 48.57 & \\
\hline \multirow{2}{*}{$\begin{array}{l}\text { Marital } \\
\text { Status }\end{array}$} & Unmarried & 13 & 8 & 61.53 & & & & 8 & 61.53 & \\
\hline & married & 257 & 148 & 57.58 & 0.079 & 1 & 119 & 46.3 & 1.153 & 0.395 \\
\hline $\begin{array}{c}\text { Education } \\
\text { primary or } \\
\text { high school } \\
\text { level }\end{array}$ & & 177 & 92 & 51.97 & & & & 67 & 37.85 & \\
\hline $\begin{array}{c}\text { Bachelor's } \\
\text { degree/ } \\
\text { master }\end{array}$ & & 93 & 64 & 68.81 & 7.087 & $0.009^{*}$ & 60 & 64.51 & 17.398 & $0.000^{*}$ \\
\hline Income & $\leq 3000$ & 115 & 57 & 49.56 & & & & 46 & 40 & \\
\hline $\begin{array}{l}\text { Yuan / } \\
\text { month }\end{array}$ & $\begin{array}{c}3000 \\
\sim 5000\end{array}$ & 103 & 59 & 57.28 & 11.003 & $0.004^{*}$ & 47 & 45.63 & 9.394 & $0.009^{*}$ \\
\hline$\geq 5000$ & & 52 & 40 & 76.92 & & & & 34 & 65.38 & \\
\hline Cancer III & & 195 & 110 & 56.41 & & & & 89 & 45.64 & \\
\hline Staging IV & & 75 & 46 & 61.33 & 0.328 & 0.587 & 38 & 50.66 & 0.373 & 0.589 \\
\hline $\begin{array}{l}\text { Medical } \\
\text { costs }\end{array}$ & $\begin{array}{l}20000 \\
\sim 40000\end{array}$ & 197 & 116 & 58.88 & & & & 93 & 47.2 & \\
\hline Yuan & $\geq 40000$ & 73 & 40 & 54.79 & 0.365 & 0.58 & 34 & 46.57 & 0.009 & 1 \\
\hline
\end{tabular}

Note: ${ }^{*} \mathrm{P}<0.05$

Table 3-2: Relationship Between Coping Style and Cancer-Related Depression, Anxiety.

\begin{tabular}{|c|c|c|c|c|c|c|c|}
\hline Variable & $\mathbf{N}$ & Active style & $\mathbf{t}$ & $\mathbf{P}$ & Negative Style & $\mathbf{t}$ & $\mathbf{P}$ \\
\hline \multirow{2}{*}{ Anxiety } & Yes 156 & $20.60 \pm 5.224$ & \multirow{2}{*}{2.77} & \multirow{2}{*}{$0.006^{*}$} & $13.07 \pm 3.943$ & \multirow{2}{*}{-6.019} & \multirow{2}{*}{$0.000^{*}$} \\
\hline & No 114 & $22.68 \pm 7.075$ & & & $10.18 \pm 3.94$ & & \\
\hline \multirow{2}{*}{ Depression } & Yes 127 & $20.63 \pm 4.577$ & \multirow{2}{*}{2.15} & \multirow{2}{*}{$0.032^{*}$} & $13.11 \pm 3.776$ & \multirow{2}{*}{-4.906} & \multirow{2}{*}{$0.000^{*}$} \\
\hline & No 143 & $22.23 \pm 7.198$ & & & $10.73 \pm 4.138$ & & \\
\hline
\end{tabular}

Multivariate Analysis of Factors Associated with CancerRelated Depression, Anxiety

Binary logistic regression showed that there were statistically significant differences in education level (OR 0.307, 95\% CI 0.1570.603), active style (OR 0.903, 95\% CI 0.859-0.948) and negative style (OR 1.298, 95\% CI 1.195-1.410) in cancer-related depression (Table 4-1). The multivariate analysis also showed that cancerrelated anxiety was associated with education level (OR 0.189, 95\% CI 0.096-0.371), active style (OR 0.926, 95\% CI 0.883-0.971) and negative style (OR 1.248, 95\% CI 1.155-1.348) (Table 4-1).

Table 4-1: Multivariate Analysis of Factors Associated with Cancer-Related Depression.

\begin{tabular}{|c|c|c|c|c|}
\hline \multirow{2}{*}{ Variable } & \multicolumn{3}{|c|}{$\mathbf{9 5 \%}$ C. I } & Lower \\
\cline { 2 - 5 } & P & OR & 0.811 & 1.965 \\
\hline Age, y & 0.302 & 1.263 & 0.164 & 2.299 \\
\hline Marital status & 0.469 & 0.614 & 0.157 & 0.603 \\
\hline Education level & $0.001^{*}$ & 0.307 & 0.381 & 1.958 \\
\hline Income & 0.852 & 0.864 & & \\
\hline
\end{tabular}




\begin{tabular}{|c|c|c|c|c|}
\hline Cancer staging & 0.99 & 1.013 & 0.131 & 7.831 \\
\hline Medical costs & 0.9 & 0.875 & 0.111 & 6.904 \\
\hline Active style & $0.000^{*}$ & 0.903 & 0.859 & 0.948 \\
\hline Negative style & $0.000^{*}$ & 1.298 & 1.195 & 1.41 \\
\hline
\end{tabular}

Note: ${ }^{*} \mathrm{P}<0.05$

\section{Discussion}

The main findings of this population-based cross-sectional study were that

a) The prevalence of ovarian cancer-related depression was $47.03 \%$ while the prevalence of cancer-related anxiety was $57.77 \%$ in western Chinese patients with ovarian cancer. Approximately $91.33 \%$ of ovarian cancer-related depression was slight and $90.38 \%$ of cancer-related anxiety was mild.

b) There were statistically significant differences in education level, income and coping style on ovarian cancerrelated depression and anxiety.

c) The multivariate analysis showed that education and coping style were the independent influencing factors of cancer-related depression and anxiety.

Chun Li Liu [12] found that the prevalence of ovarian cancerrelated depression was $47 \%$ and the anxiety was $51.5 \%$, which was similar to the present study. But Price M A [24] performed a prospective cohort study which enrolled 798 Australian ovarian cancer patients and reported that the clinical anxiety was $15 \%$ and depression was only 5.9\%. And a meta-analysis indicated that the prevalence of symptoms of depression and anxiety in Chinese cancer patients was $54.90 \%$ and $49.69 \%$ [25], respectively, which was not limited to ovarian cancer. Moreover, a systematic review has shown that the prevalence of depression and anxiety in women with ovarian cancer is significantly greater than healthy female [26]. Therefore, it suggests that the Chinese ovarian cancer patients have relatively higher levels of anxiety and depression. Besides, in our study, ovarian cancer-related anxiety level was slightly higher than depression level. It is consistent with the results of Mielcarek P [27] in 2016, which also found that the level of anxiety was higher than depression in patiens from Poland with advanced ovarian cancer, and the prevalence of pathological anxiety was the highest(74\%) prior to surgery. All the patients participated in our study were advanced stage of ovarian cancer, too. Another study [28] showed that the prevalence of depression in Chinese patients with malignant tumors was 54.90\%. And Hu Hong [29] reviewed 35 studies about cancer-related depression in china, a total of 7445 cases of cancer patients were included and found the prevalence of cancer depression was ranged from $19 \%$ to $95 \%$. So, there is no doubt that the sample size, stage of cancer, and choice of assessment tools are the factors that lead to the different results between our study and previous studies. In developed countries, the improved recognition of psychological impact from ovarian cancer may lead workers seeking for mental treatment and other social supports actively.

In the study, we found that ovarian cancer-related depression and anxiety are associated with education level, income and coping style. Education and coping style were the independent influencing factors. Binary logistic regression analysis showed that the factors associated with ovarian cancer-related depression were education level, active style and negative style. And cancer-related anxiety was also associated with education level, active style and negative style. Liu CL [12] found ovarian cancer patients with the higher education levels were tended to have a lower prevalence of cancer-related depression. But another study [30] reported the opposite result which were consistent with the findings of our study. The reason may be that the patients with higher educational levels often took the initiative to get knowledges of cancer relevant information, but the poor prognosis of ovarian cancer gave rise to the symptoms of depression and anxiety. Patients with lower educational levels were tended to dependent on medical institutions and medical staff more and cooperate with the diagnosis and treatment actively. Wang hong-qiao[31] found that the symptoms of depression and anxiety in ovarian cancer patients were positively correlated with negative coping and negatively correlated with positive coping which were consistent with the findings of our study. The reason may be that coping style has played a regulatory and mediating role between stress and psychological response. Previous studies [32] have shown that patients who actively coping with problems are prone to optimism emotion. Several studies have provided evidence for the influence of positive psychological factors in cancer patients [33-35], and a meta-analysis [36] have shown that psychological intervention can significantly reduce the anxiety and depression of ovarian cancer patients. This means that clinical staffs should make more efforts to provide health education on coping style and psychological intervention to ovarian cancer patients.

\section{Limitations}

Our study has several limitations. Firstly, we didn't compare the differences of anxiety and depression levels in patients with early and advanced ovarian cancer and explore the associations between the psychological and stage of ovarian cancer. Secondly, we only focused on the symptoms of depression and anxiety, other psychological disorders, such as post-traumatic stress disorders, obsession and inferiority, have not been investigated. Thirdly, the study adopted convenient sampling method and conducted in only one hospital, the extrapolation of research results was limited. So, additional well-designed studies with multi-center and rigorous methodologies are required. 


\section{Conclusion}

Our findings highlight that about half of ovarian cancer patients suffered from cancer-related depression and anxiety, more than $90 \%$ of depression, anxiety was mild. Among them education level, coping style were significant and independent determinants. It is essential to ensure that the health care system provides efficient health education, psychological intervention and support. In particular, clinical staff should pay more attention to the mood of ovarian cancer patients, early detection of cancer-related depression and anxiety, to promote the mental health of ovarian cancer patients.

\section{Acknowledgements}

The study was enabled by the nurses at West China Second University Hospital, Sichuan University. We are grateful to all the participants for their comments and contributions. We thank all those who agreed to be investigated for this project. We would like to express our sincere appreciating to Prof. Jianhua Ren for editing this manuscript.

\section{Disclosure Statement}

The authors declare no competing interests.

\section{References}

1. Sankaranarayanan R, Ferlay J (2006) Worldwide burden of gynaecological cancer: the size of the problem[J]. Best practice \& research Clinical obstetrics \& gynaecology 20(2): 207-225.

2. Wang B, Liu SZ, Zheng RS, Zhang F, Chen WQ et al. (2014) Time trends of ovarian cancer incidence in China. Asian Pac J Cancer Prev 15: 191-193.

3. Mitra R, Chen X, Greenawalt EJ, Maulik U, Jiang W, et al. (2017) Decoding critical long non-coding RNA in ovarian cancer epithelial-tomesenchymal transition. Nat. Commun 8: 1604.

4. (2010) US Cancer Statistics Working Group. United States cancer statistics: 1999-2006 incidence and mortality web-based report[J]. US Department of Health and Human Services, Centers for Disease Control and Prevention and National Cancer Institute, Atlanta, USA.

5. (2016) Australian Institute of Health and Welfare. Australian Cancer Incidenceand Mortality (ACIM) books: Ovarian Cancer.

6. Razi S, Ghoncheh M, Mohammadian-Hafshejani A, Aziznejhad H4, Mohammadian M, et al. (2016) The incidence and mortality of ovarian cancer and their relationship with the Human Development Index in Asia[J]. ecancermedicalscience : 10.

7. (2007) Novak E Berek \& Novak's gynecology[M]. Lippincott Williams \& Wilkins.

8. Aneta U R, Bolenna KB,Sebastian W, Tomasz K (2018) Survival rates among women with ovarian cancers diagnosed in the area of Podkarpacie province in the years 1990-2015.Contemp Oncol (Pozn) 22(3): 151-157.

9. Al QM, Al KM (2016) Prevalence of symptoms and quality of life among Jordanian cancer patients. Clin Nurs Res[J] 25(2): 174.

10. Nipp RD, Powell E, Chabner B, Beverly Moy (2015) Recognizing the financial burden of cancer patients in clinical trials. Oncologist[J] 20(6): 572-575.

11. Mitchell AJ, Chan M, Bhatti H, Halton M, Grassi L, et al. (2011) Prevalence of depression, anxiety, andadjustment disorder in oncological, haematological, and palliative-caresettings: a meta-analysis of 94 interview-based studies. Lancet Oncol 12: 160-174.
12. Liu C L, Liu L, Zhang Y, Dai XZ, Wu H (2017) Prevalence and its associated psychological variables of symptoms of depression and anxiety among ovarian cancer patients in China: a cross-sectional study[J]. Health and quality of life outcomes 15(1): 161.

13. Yang YL, Liu L, Wang Y, Wu H, Yang XS, et al. (2013) The prevalence of depression and anxietyamong Chinese adults with cancer: a systematic review and meta-analysis. BMC Cancer 13: 393.

14.(2013) American Psychiatric Association. Diagnostic and statistical manual of mental disorders. $\left(5^{\text {th }} \mathrm{edn}\right)$. The Association, Washington (DC), USA.

15. Linden W, Vodermaier A, Mackenzie R, Greig D (2012) Anxiety and depression after cancerdiagnosis:prevalence rates by cancer type, gender, and age.Journal of Affective Disorders 141(2-3): 343.

16. Peteet JR, Balboni MJ (2013) Spirituality and religion in oncology. CA Cancer J Clin 63(4): 280-290.

17. Herzog T J, Wright J D (2007) The impact of cervical cancer on quality of life-The components and means for management. Gynecologic Oncology 107(3): 572-577.

18. Di Mattei VE, Carnelli L, Bernardi M, Rebecca Bienati, Chiara Brombin, et al. (2018) Coping Mechanisms, Psychological Distress, and Quality of Life Prior to Cancer Genetic Counseling. Front Psychol 16(9): 1218.

19. Price MA, Butow PN, Costa DSJ, King MT, Aldridge LJ, et al. (2010) Prevalence and predictors of anxiety and depression in women with invasive ovarian cancer and their caregivers[J]. The Medical Journal of Australia 193(5): 52.

20. Yang YL, Liu L, Wang Y, Yang XS, Wang JN, et al. (2013) The prevalence of depression and anxiety among Chinese adults with cancer: a systematic review and meta-analysis. BMC Cancer 13: 393.

21.Sam W, Philip P, Jessica M, Natalie Mc Leod, George Lewith (2015) Depression and anxiety in ovarian cancer: a systematic review and meta-analysis of prevalence rates. Bmj Open 5(11): e007618.

22. Mielcarek P, Nowicka Sauer K, Kozaka J (2016) Anxiety and depression in patients with advanced ovarian cancer: a prospective study[J]. Journal of Psychosomatic Obstetrics \& Gynecology 37(2): 57-67.

23. Yang Y L, Liu L, Wang Y, Yang XS, Wang JN, et al. (2013) The prevalence of depression and anxiety among Chinese adults with cancer: a systematic review and meta-analysis. BMC Cancer 13(1): 393-408.

24. Hong H, Gong C (2015) Prevalence of depression in Chinese patients with malignant tumor and its related factors. Chinese Journal of Clinical Oncology and Rehabilitation 22(8): 1020-1021.

25. Ming D, Jiali Z, Qilin F (2010) The efficacy of anti-depression treatment on 286 patients with malignant tumor. China Oncology 20(11): 857-859.

26. Hongqiao W, Yanlan M, Xu L (2014) Investigation on anxiety, depression and coping styles for patients with bone tumour during chemotherapy. China Medical Herald 11(5): 112-115.

27. Susan KL, Eileen S, Jeanne C, Susan Leighton, Keith Baggerly, et al. (2017) Quality of Life among Long-Term Survivors of Advanced Stage Ovarian Cancer: A Cross-Sectional Approach, Gynecol Oncol 146(1): 101-108.

28. Yang YL, Liu L, Li MY, Shi M, Wang L (2016) Psychological disorders and psychosocial resources of patients with newly diagnosed bladder and kidney cancer: a cross-sectional study. PLoS One 11: e0155607.

29. Wu HX, Zhong H, Xu YD, Cui-Ping Xu, Ying Zhang, et al. (2016) Psychological and behavioral intervention improves the quality of life and mental health of patients suffering from differentiated thyroid cancer treated with postoperative radioactive iodine- 131 . Neuropsychiatr Dis Treat 12: 1055-1060.

30. Costa AL, Heitkemper MM, Alencar GP, Damiani LP, Silva RMD, et al. (2016) Social support is a predictor of lower stress and higher quality of life and resilience in Brazilian patients with colorectal cancer. Cancer Nurs. 
31. Xuefei W, Lixin H (2014) Influence of psychological intervention on the anxiety and depressive symptoms for patients with ovarian cancer in China:a Meta- analysis. Modern Medical Journal 43(3): 248-252.

32. Tercyak KP, Lerman C, Peshkin BN, Hughes C, Main D, et al. (2001) Effectsof coping style and BRCA1 and BRCA2 test results on anxiety amongwomen participating in genetic counseling and testing for breast andovarian cancer risk. Health Psychol 20: 217-222.

33. Stewart SL, Rim SH, Trivers KF (2010) Summaryand impact of ovarian cancer research andprogrammatic activities at the Centers forDisease Control and Prevention. J WomensHealth (Larchmt) 19(8): 1427-1432.

ISSN: $2574-1241$

DOI: $10.26717 /$ BJSTR.2020.26.004404

Jing Chen. Biomed J Sci \& Tech Res

(C) This work is licensed under Creative Submission Link: https://biomedres.us/submit-manuscript.php
34. Fairley TL, Pollack LA, Moore AR, Smith JL (2009) Addressing cancer survivorship through public health: an updatefrom the Centers for Disease Control andPrevention. J Womens Health (Larchmt) 18(10): 1525-1531.

35. Zigmond AS, Snaith RP (1983) The hospital anxiety and depression scale. ActaPsychiatr Scand 67: 361-370.

36. Xie YN (1999) Simplified coping style questionnaire. Chin Ment Health J 13(Suppl): 122-124

\begin{tabular}{ll} 
BIOMEDICAL & Assets of Publishing with us \\
RESEARCHES & - Global archiving of articles \\
& - Immediate, unrestricted online access \\
\hline ISSN: $2574-1241$ & - Rigorous Peer Review Process \\
&
\end{tabular}

